\title{
Pill Burden in Hypertensive Patients Treated with Single-Pill Combination Therapy - An Observational Study
}

\author{
Andreas Hagendorff · Siegfried Freytag · Alfons Müller · Sven Klebs
}

To view enhanced content go to www.advancesintherapy.com Received: February 4, 2013 / Published online: March 25, 2013

(c) The Author(s) 2013. This article is published with open access at Springerlink.com

\section{ABSTRACT}

Introduction: Hypertension is a condition which in many cases is treated with more than one drug. Additionally, patients with hypertension often suffer from other concomitant diseases, such as diabetes mellitus or dyslipidemia, which adds to the number of pills that patients need to take (pill burden). The aim of this study was to investigate the impact of this pill burden on patients with hypertension in clinical practice in Germany.

\footnotetext{
A. Hagendorff $(\bowtie)$

Department of Cardiology-Angiology, University

Hospital Leipzig, 04103 Leipzig, Germany

e-mail: andreas.hagendorff@medizin.uni-leipzig.de

S. Freytag

Clinical Research, Kantar Health GmbH, Landsbergerstr. 284, 80687 München, Germany

A. Müller · S. Klebs

Clinical and Regulatory Affairs, Novartis Pharma

GmbH, Roonstr. 25, 90429 Nürnberg, Germany
}

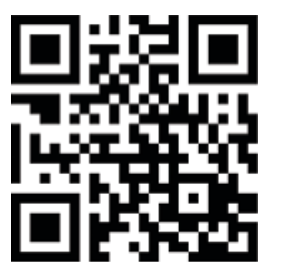

Enhanced content for Advances in Therapy articles is available on the journal web site: www.advancesintherapy.com
Methods: This prospective, open-label, observational study enrolled adult patients for whom their physician considered treatment with a single-pill combination of amlodipine, valsartan, and hydrochlorothiazide as indicated. At the start of the observation period, physicians and patients filled in a respective questionnaire. Results: The questionnaires of 7,101 patients and 905 physicians were analyzed. The survey among the patients showed that the majority of patients felt burdened by the high number of pills to be taken. This was also seen as a potential reason for medication errors. Approximately half of the patients would be willing to make an out-of-pocket payment for reducing the number of pills to half. The results of the physician questionnaire indicate that the physicians were well aware of the set of problems that is generally associated with the high pill burden and that there is a clear willingness to use combination products in order to reduce the pill burden.

Conclusion: A high number of pills is considered a burden by the patients. This burden increases with the number of pills taken per day.

Keywords: Amlodipine; Cardiology; Combination therapy; Germany; Hydrochlorothiazide; 
Hypertension; Observational study; Pill burden; Triple therapy; Valsartan

\section{INTRODUCTION}

Hypertension is one of the main risk factors for cardiovascular diseases [1]. Its prevalence has increased worldwide and is predicted to further increase $[1,2]$. This situation is further complicated by the fact that a considerable percentage of patients with hypertension have not been diagnosed as such and are, thus, not under treatment. A large portion of treated patients do not reach target blood pressure [3]. The results of a meta-analysis of 147 randomized studies underline the importance of blood pressurelowering treatments. For each reduction by $10 \mathrm{mmHg}$ in systolic blood pressure or by $5 \mathrm{mmHg}$ in diastolic blood pressure, a $22 \%$ reduction in events due to coronary heart disease and a $41 \%$ reduction in stroke was observed [4].

Results of controlled studies show that blood pressure adjustments to values below $140 / 90 \mathrm{mmHg}$ are possible, even if two or more antihypertensive drugs are needed [5-9]. Another meta-analysis, using 63 studies (including 6 studies in hypertension) showed that patients with high adherence to their treatment schedule have a much higher chance to reach target blood pressure than patients with low adherence to treatment schedule (odds ratio [OR] 3.44; 95\% confidence interval [CI] 1.60, 7.37). [10]. This confirms the important role of compliance/adherence in reaching the target blood pressure and in avoiding cardiovascular events [11].

One factor that has a major influence on treatment compliance is the so-called pill burden, i.e., the number of pills the patient needs to take per day. Studies have indicated that higher pill burden led to decreased treatment compliance $[12,13]$.

In many cases, hypertension is not the only condition that a given patient suffers from.
Diabetes mellitus, and disorders of the lipid metabolism and the metabolic syndrome are major concomitant diseases found in patients with hypertension [14]. Because of these comorbidities, the use of multiple drugs is common and is recommended by international guidelines $[14,15]$.

The aim of the present noninterventional study SIMPLIFY (Nicht-interventionelle Studie mit Exforge $\mathrm{HCT}^{\circledR}$ zum Einfluss der Polypharmakotherapie auf Hypertoniker; a noninterventional study with Exforge HCT $^{\circledR}$ concerning the influence of polypharmacy on patients with hypertension) was to investigate how both patients with hypertension and their treating physicians deal with the high numbers of pills, and what kind of challenges they are facing.

Additionally, the SIMPLIFY study aimed to estimate the effectiveness of a single-pill triple therapy with amlodipine, valsartan, and hydrochlorothiazide $(\mathrm{A}+\mathrm{V}+\mathrm{H})$ in routine practice. These results will be the focus of a separate publication.

\section{MATERIALS AND METHODS}

\section{Study Design}

The SIMPLIFY study was conducted as a prospective, open-label, observational, multicenter study between November 2009 and November 2010 in practices of 1,269 general practitioners and internists in Germany. The study was notified in accordance with § 67 (6) German Drugs Law (AMG) and conducted according to the applicable regulatory requirements and recommendations. All procedures followed were in accordance with the ethical standards of the responsible committee on human experimentation (institutional and national) and with the Helsinki Declaration 
of 1975, as revised in 2000, and as far as applicable for observational, noninterventional studies. Informed consent was obtained from all patients for being included in the study. The participating physicians received a compensation for the documentation of each patient in accordance with the official scale of physicians' fees (Gebührenordnung für Ärzte, GOÄ). The study was approved by the respective Ethics Committee.

Patients were treated according to medical and therapeutic needs. The procedures and decisions of the physicians were not influenced and the temporal frequency of examinations was to be according to practice routine. Additional examinations exceeding the usual scope were not required.

\section{Study Population}

Patients of either gender suffering from essential hypertension for whom treatment with $\mathrm{A}+\mathrm{V}+\mathrm{H}$ was indicated according to the physician's opinion were included into this noninterventional study. There were no additional inclusion criteria (e.g., severity of hypertension). There were no predefined exclusion criteria, except for the contraindications mentioned in the respective summary of product characteristics (SmPC). All dosages of $\mathrm{A}+\mathrm{V}+\mathrm{H}$ available in the German market could be used.

\section{Study Conduct and Assessments}

The observational period per patient was approximately 3-4 months. An examination was to be documented by the physician at the start and the end of the observation period. Optionally, physicians could document an additional visit in between. At the start of the observational period, patients filled in a questionnaire concerning the influence of the number of pills (nine items) and physicians filled in a questionnaire concerning the impact of the number of pills in daily practice (six items). Details on the questions are given in Table 1. At the end of the study, effectiveness and tolerability was assessed by the physician. Adverse events (AEs) were reported during the whole study according to local regulations.

It was the aim of the SIMPLIFY study to evaluate the two questionnaires collected at baseline, and the effectiveness and safety/ tolerability of $\mathrm{A}+\mathrm{V}+\mathrm{H}$. Additional parameters documented in the study included demographic and diagnostic data, cardiovascular risk factors, prior and concomitant diseases relevant to the indication, information on potential antihypertensive pretreatment, and total number of pills (overall and for treatment of hypertension). Vital signs were assessed according to clinical practice and documented as well as $\mathrm{A}+\mathrm{V}+\mathrm{H}$ dose, and antihypertensive concomitant medication at the start and the end of the observation period, and the optional visit in between.

The data in all documentation forms were examined for their plausibility by the data management department. Additionally, for a defined percentage $(2 \%$, in line with common practice in Germany [16]) of randomly chosen study centers, the documentation forms were compared with the source documents during on-site monitoring.

\section{Data Analysis}

According to the predefined statistical analysis plan, the statistical evaluation was carried out using basic descriptive statistical methods and was interpreted in an explorative way. In the publication, the results of the overall population is shown as well as analyses based on the number of pills. 
Table 1 Patient questionnaire (a) and physician questionnaire (b) (continued on next page)

(a)

\section{Patient questionnaire}

\section{No. Questions/items}

1) Having to take several pills per day is a burden for me.

2) The number of pills I have to take has an influence on how sick I feel.

3) Do you need help to prepare the intake of tablets for the day/week at home?

4) In case you prepare the intake of your drugs yourself, what is the mean amount of time needed on average per day for this task?

5) a. Are pill color and shape a significant help for orientation during drug intake?

b. If yes to the previous question: The correct use of drugs is harder for me when their appearance changes, e.g., caused by a change in compound.

6) I am worried that I erroneously forget pills or take the wrong pills/the wrong dose.

7) a. Does it happen that you are uncertain about whether you have already taken your pills or not?

b. If yes to the previous question: How often does this happen?

8) If it was theoretically possible to change your pill count while keeping the quality of your medical care unchanged - what maximal number of pills per day would you consider your personal acceptable limit?

9) a. If it was theoretically possible to halve your pill Yes count while keeping the quality of your medical care unchanged - would you be prepared to make an additional out-of-pocket payment for this?

b. If yes to the previous question: What amount would you be willing to pay additionally?

Yes

Yes

\section{Potential answers}

$\begin{array}{llll}\begin{array}{l}\text { Strongly } \\ \text { agree }\end{array} & \text { Agree } & \text { Disagree } & \begin{array}{l}\text { Strongly } \\ \text { disagree }\end{array} \\ \begin{array}{l}\text { Strongly } \\ \text { agree }\end{array} & \text { Agree } & \text { Disagree } & \begin{array}{l}\text { Strongly } \\ \text { disagree }\end{array} \\ \text { Yes } & & \text { No } & \end{array}$

(Min)

No

\begin{tabular}{|c|c|c|}
\hline $\begin{array}{l}\text { Strongly } \\
\text { agree }\end{array}$ & Agree & Disagree \\
\hline
\end{tabular}

Strongly

Agree

Disagree

Strongly

agree

disagree

No

Often

Sometime

Rarely

Very rarely

(Number)

No limit

No

Up to $10 €$

Up to $20 €$

Up to $50 €$

More than permonth permonth permonth permonth

$50 €$ per month 
Table 1 Continued

(b)

Physician questionnaire

No. Questions

1) The number of pills that chronically ill patients have to take daily is a challenge for me in the daily treatment routine.

2) In the daily treatment routine, chronically ill patients describe a high number of pills as a burden.

3) I am informed about the importance of the topic "number of pills and treatment adherence (compliance/persistence) and the associated impact."

4) I would like more information about the topic

"number of tablets and treatment adherence (compliance/persistence) and the associated impact."

If possible, I prefer combination products because they help me to reduce the number of tablets my patients have to take every day.

6) For my patients, I consider the benefit of the triple combination of $\mathrm{A}+\mathrm{V}+\mathrm{H}$ in reducing the number of tablets to be as follows:
Potential answers

Strongly Agree

agree

Disagree

Strongly

disagree

Strongly Agree

agree

Strongly Agree

agree

Disagree

Strongly

disagree

Strongly

Agree

agree

Disagree

Strongly

disagree

Strongly

Agree

agree

Disagree

Strongly

disagree

Very high High Fair Low

$A+V+H$ amlodipine, valsartan, and hydrochlorothiazide

For some questions additional subgroups (age and concomitant disease) are presented. The statistical evaluation was carried out using SAS $^{\circledR}$ Version 9.2 for Windows, (SAS Institute, Cary, North Carolina, USA).

\section{RESULTS}

\section{Baseline Characteristics}

Patients were enrolled in 905 practices in Germany. For 7,181 patients, filled-in questionnaires were available. Of these, 7,101 patients were analyzed.

Slightly more than half of the patients were male and $>60$ years old. Only about a third of the patients reported diabetes mellitus (Table 2). At the start of observation (before the physicians had changed the patients' medication to the singlepill triple therapy with $\mathrm{A}+\mathrm{V}+\mathrm{H})$, the patients were taking $4.9 \pm 3.1$ pills (mean \pm standard deviation [SD]) per day for the treatment of any indication (median: 4.0 pills) and $3.1 \pm 2.0$ pills (mean \pm SD) per day of these for treatment of hypertension (median: 3.0 pills). Slightly more than a quarter of the patients were taking $\geq 6$ pills (Table 3 ).

\section{Patient Questionnaire}

Patients of either gender suffering from essential hypertension for whom treatment with $\mathrm{A}+\mathrm{V}+\mathrm{H}$ was indicated according to the 
Table 2 Baseline demographics and characteristics $(n=7,101)$

\begin{tabular}{ll}
\hline & $\begin{array}{l}\text { Mean } \pm \text { SD or } \\
n(\%)\end{array}$ \\
\hline Gender & \\
Male & $3,677(51.8)$ \\
Female & $3,250(45.8)$ \\
Missing & $174(2.5)$ \\
Age (years) & $64.8 \pm 11.4$ \\
$<50$ & $695(9.8)$ \\
$\geq 50-<60$ & $1,564(22.0)$ \\
$\geq 60-<70$ & $2,153(30.3)$ \\
$\geq 70-<80$ & $1,998(28.1)$ \\
$\geq 80$ & $654(9.2)$ \\
Missing & $37(0.5)$ \\
Diabetes & $2,411(34.0)$ \\
Patients with specification \\
diabetes mellitus
\end{tabular}

physician's opinion were included into this noninterventional study. At the start of the observational period (i.e., before being treated with $\mathrm{A}+\mathrm{V}+\mathrm{H})$, patients filled in a questionnaire concerning the influence of the high number of pills (nine items) and physicians filled in a questionnaire concerning the impact of the high number of pills on the daily practice (six items).

\section{Burden and Perception of Disease}

When asked, the majority of patients stated that having to take several pills per day was a burden for them (Fig. 1). This percentage increased considerably with an increasing number of pills per day. Similarly, the number of pills per day
Table 3 Total number of pills per day before start of therapy

\begin{tabular}{lll}
\hline & \multicolumn{2}{l}{$\begin{array}{l}\text { Total number of pills per day (any } \\
\text { indication) }\end{array}$} \\
\hline Total & $n$ & $\%$ \\
\hline No pills & 7,101 & 100.0 \\
$\leq 3$ & 191 & 2.7 \\
$>3-\leq 6$ & 2,466 & 34.7 \\
$>6$ & 2,554 & 36.0 \\
Missing & 1,827 & 25.7 \\
\hline
\end{tabular}

seemed to have an influence on how sick the patients felt. The percentage of patients agreeing to the statement "The number of pills I need to take influences how sick I feel" was clearly lower in patients taking $\leq 3$ pills per day (strongly agree: $18.0 \%$; agree: $32.6 \%$ ) than in patients taking $>6$ pills per day (strongly agree: $37.4 \%$; agree: $32.5 \%)$.

\section{Need for Assistance and Expenditure of Time Concerning Management of Medication}

The majority of patients (overall $85.7 \%$ of patients) stated that they did not need any help to prepare the intake of pills for the day/week at home (Table 1, patient questionnaire, item 3). The higher the number of pills, the more patients needed help, i.e., $22.8 \%$ needed help in patients with $>6$ pills a day, whereas only $6.1 \%$ needed help in patients with $\leq 3$ pills.

Approximately two thirds of the patients $(62.6 \%)$ stated that the average time needed for the preparation of pill intake was 5 min or less. The percentage of patients who needed more than 10 min for this task increased with increasing number of pills. A clear increase was seen between $\leq 3$ pills and $>3$ pills: for $\leq 3$ pills only $4.4 \%$ of patients needed more than $10 \mathrm{~min}$, 


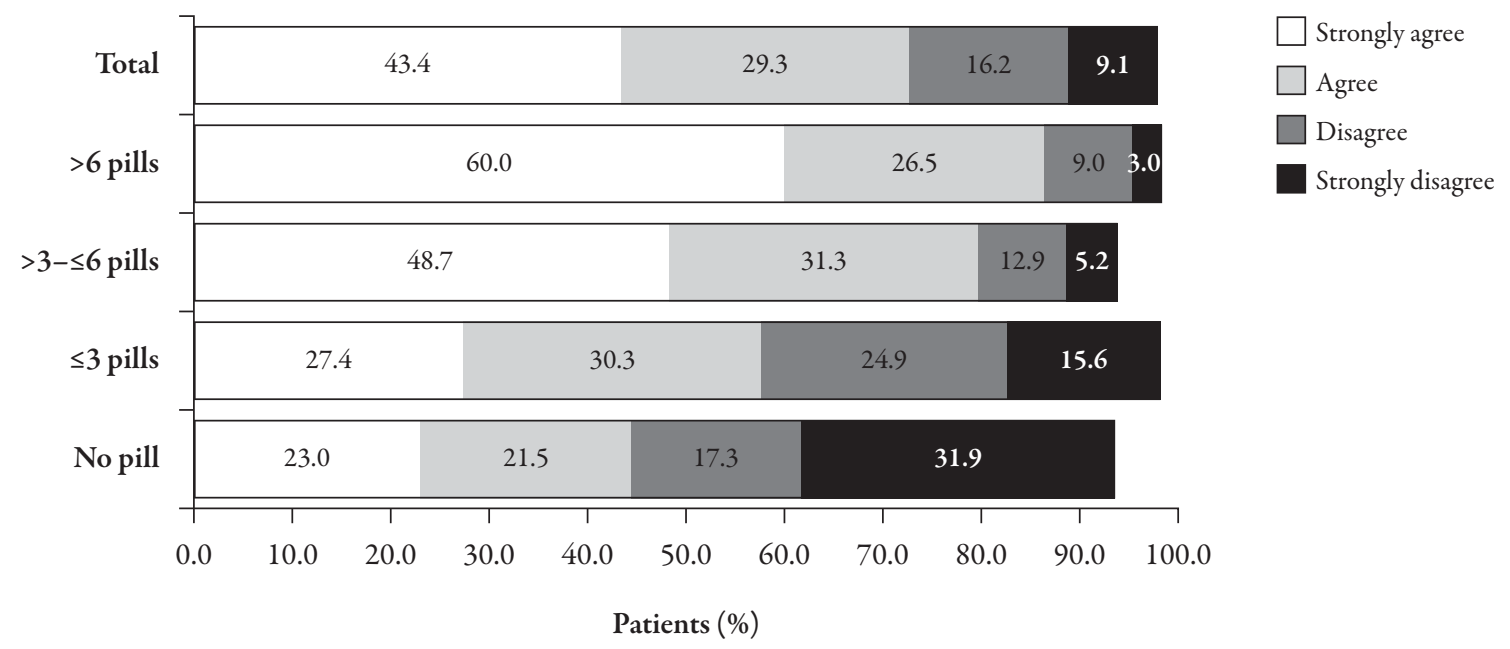

Fig. 1 Patient questionnaire: answers to item 1, "Having to take several pills per day is a burden for me." Note: the percentages do not always add up to $100 \%$ as the answer to this item on the questionnaire was missing for a certain number of patients

while for $>3$ pills, $10 \%$ of patients needed more than $10 \mathrm{~min}$.

As expected, the percentage of patients who needed more than $10 \mathrm{~min}$ also increased with increasing age, reaching a value of $20.8 \%$ in $>79$ year olds.

\section{Impact of Pill Color and Shape/Change of Compound}

The color and shape of the pills appeared to play an important role as guidance for the intake of pills (Table 1, patient questionnaire, item $5 \mathrm{a}$ ) in the majority of patients (74.3\%). In this context, the importance of color and shape increased with the number of pills that patients had to take. A total of $82.2 \%$ of the patients who were taking $>6$ pills considered color and shape an important landmark, in contrast to $67.6 \%$ of patients who were taking $\leq 3$ pills.

Concerning age, the importance attributed to color and shape is higher in older $(83.8 \%$ in $\geq 80$ year olds) than in younger patients $(64.9 \%$ in $<50$ year olds).

Another issue in the context of color and shape was the question of whether the correct use of the medication is harder for the patients when the medication's appearance changes (e.g., caused by a change in compound or triggered by changes in rebate contracts of health insurances with pharmaceutical companies; Table 1, patient questionnaire, item $5 b)$. The majority of patients (79.4\%) claimed that this was the case. As even the younger patients $(<50$ years) stated this in the majority of cases $(66.3 \%)$, it is not surprising that $89.6 \%$ of the oldest subgroup ( $\geq 80$ year olds) agreed that the correct use of the medication is harder when the appearance changes.

Consequently, there is also a clear correlation between the current pill burden and the problems that patients expect when they change to another compound with a different appearance, as shown in Fig. 2.

Approximately half of the patients stated that they were concerned about accidentally forgetting pills, or taking the wrong pills or the wrong dose of their pills. An increasing number of pills (i.e., increasing pill burden) aggravates the situation (Table 1, patient questionnaire, item 6; Fig. 3). 


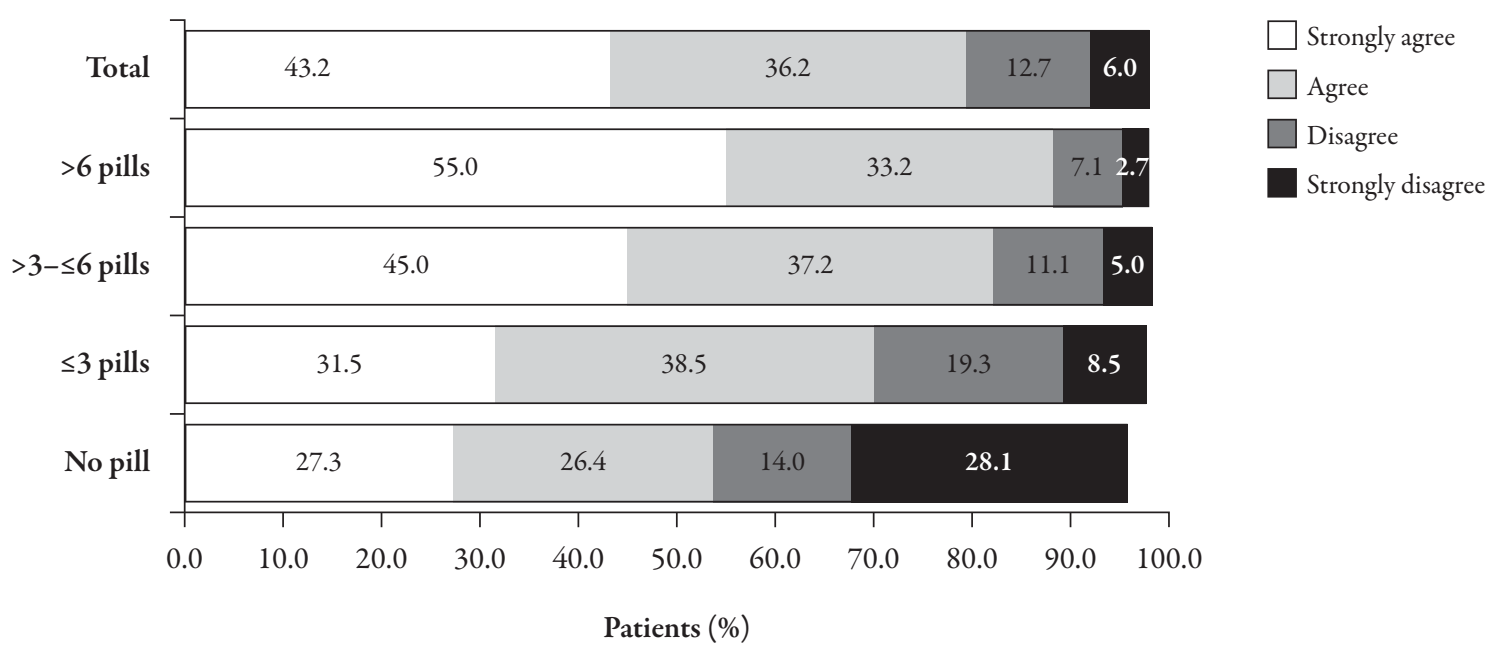

Fig. 2 Patient questionnaire: answers to item 5b, "If yes to the previous question (Are pill color and shape a significant help for orientation during drug intake?): the correct use of drugs is harder for me when their appearance changes, e.g., caused by a change in compound." Note: the percentages do not always add up to $100 \%$ as the answer to this item on the questionnaire was missing for a certain number of patients

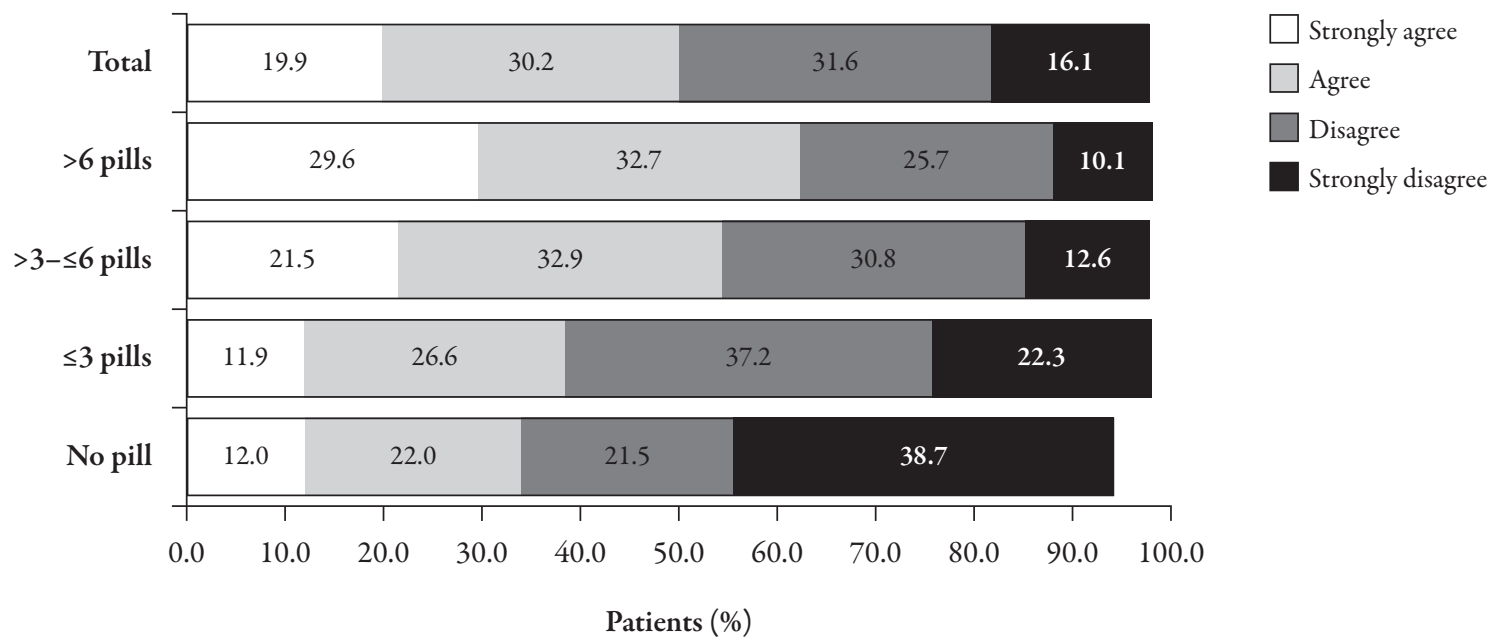

Fig. 3 Patient questionnaire: answers to item 6, "I am worried that I erroneously forget pills or take the wrong pills/the wrong dose." Note: the percentages do not always add up to $100 \%$ as the answer to this item on the questionnaire was missing for a certain number of patients

Similarly, concern about medication errors is of higher relevance in older patients $(\geq 80$ year olds: $66.9 \%)$ than in younger patients $(<50$ year olds: $36.2 \%)$.

In fact, $59.3 \%$ of the patients admitted that they had already been uncertain at times whether they had already taken their pills or not. When asked how often this had happened,
$56.9 \%$ answered that this had happened at least occasionally. Higher numbers of pills per day also lead to higher percentages of patients who claimed that they had often or occasionally been uncertain whether they had already taken their pills or not ( $\leq 3$ pills per day: $6.1 \%$ often and $41.7 \%$ occasionally; $>6$ pills per day: $16.5 \%$ often and $48.6 \%$ occasionally). 


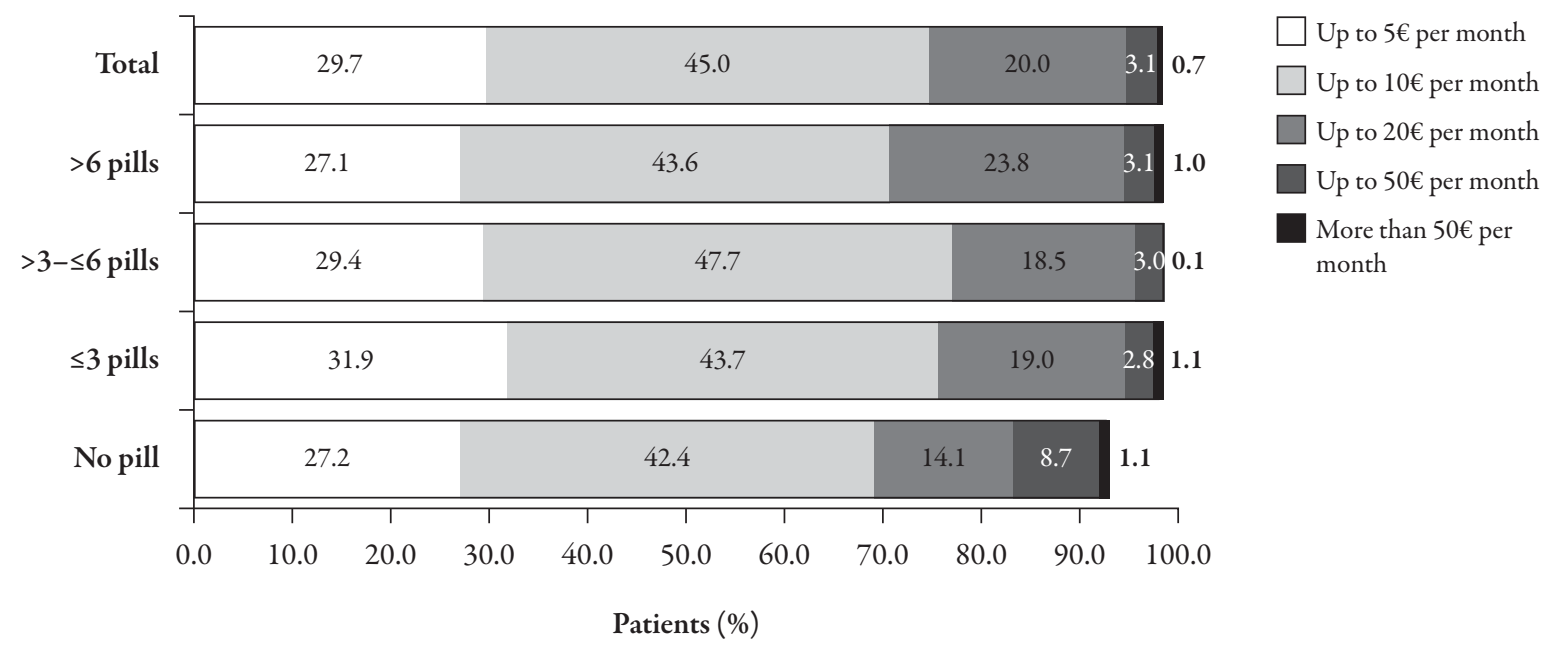

Fig. 4 Willingness to make an additional out-of-pocket payment for halving the number of pills. Note: the percentages do not always add up to $100 \%$ as the answer to this item on the questionnaire was missing for a certain number of patients

When asked "What maximal number of pills per day would you consider your personal acceptable limit when it is possible to have the same standard of care?" $10.9 \%$ defined 1 pill, $18.0 \%$ defined 2 pills, and $18.3 \%$ defined 3 pills as the limit. About a quarter of patients (24.5\%) stated that there was no limit.

\section{Willingness to Make an Additional Out-of- Pocket Payment}

The fact that a high number of pills to be taken daily constitutes a massive burden for the patients is further highlighted by the fact that more than half of the patients $(50.6 \%)$ would be willing to make additional out-ofpocket payments if this would result in having to take only half as many pills with the same standard of medical care. This statement was mostly independent of the actual pill burden and the age of the patients. In patients taking $\leq 3$ pills, $46.1 \%$ would be willing to make additional payments, and in patients taking $>6$ pills, $54.2 \%$ would be willing to make additional payments.

When asked about the amount of money that they would be willing to pay additionally, most patients would be willing to pay up to 10 Euro $(€)$ per month (see Fig. 4).

\section{Subgroups}

The results of the patient questionnaire were further evaluated with regard to specific subgroups by age, gender, and the presence of additional diseases, such as diabetes mellitus. A number of subgroups showed a consistently higher level of agreement with the statements made in the questionnaire than other subgroups. As already specified before, these were the elderly patients (especially those $\geq 80$ years old), patients with a high pill burden, and patients suffering from diabetes mellitus.

\section{Physician Questionnaire}

A total of 905 physicians' questionnaires were analyzed. The results of the physician questionnaire suggest that pill burden in chronically ill patients also constitutes a challenge for the physicians. When asked, a total of $93.6 \%$ of physicians strongly agreed or agreed to the respective statement. Patients seem to actively address the issue and expected guidance 
from their physicians. The vast majority of physicians (95.8\%) strongly agreed or agreed that in the daily practice the chronically ill patients described the high number of pills as a burden.

Most physicians regarded themselves as well informed on the importance of the topic "number of pills to be taken and compliance," and its impact (98.1\% strongly agreed or agreed), and did not wish to receive to receive more information on the topic (62.8\%).

In line with these statements, the vast majority of physicians (95.7\%) also stated that - whenever possible - they preferred the used of combination products, because these helped reduce the number of pills that their patients had to take. When asked specifically about their assessment of the usefulness of the triple combination $(\mathrm{A}+\mathrm{V}+\mathrm{H})$, the vast majority of physicians answered with "high" (38.9\%) or "very high" (58.9\%).

\section{DISCUSSION}

The present study summarized the results of a noninterventional study in patients with hypertension. The aim of the study was to investigate how patients with hypertension and their treating physician dealt with the often high number of pills, and what kinds of challenges they were facing.

The patient questionnaire in the present study showed that patients consider having to take several pills per day a burden and that this also had an influence on how sick they feel. This was also corroborated by the physicians' questionnaire. The vast majority of physicians reported that in daily practice the chronically ill patients described the high number of pills a burden.

This effect is more pronounced in patients with a higher number of pills than in those with a lower number of pills. Elderly patients and patients suffering from diabetes mellitus are additional subgroups who seem to be more prone to regarding a high number of pills per day as a burden. This may be related to the fact that these subgroups may also be prone to having a higher pill burden than younger patients and patients not suffering from diabetes mellitus.

The present study also showed that the physicians were aware of the problems that are generally associated with the high pill burden and the effect it had on compliance. The vast majority of physicians stated that they were prepared to prescribe combinations in order to reduce the pill burden. Nevertheless, this seems to have little effect on daily practice as the patients were taking an average of 5 pills per day and more than a quarter of the patients were taking $\geq 6$ pills. The reasons for this discrepancy need to be elucidated and potential solutions identified. One potential solution could be to improve the knowledge of physicians on how to best treat hypertension, with an important goal being to increase patient compliance. Studies have shown that physicians who have been specifically trained in the guidelines on the treatment of hypertension more often achieved target blood pressure in their patients than physicians who had not received training [17], and that patients of trained physicians showed a significantly higher compliance than patients of physicians who had not been specially trained [18].

In addition to the physician, patient compliance is also a key factor when it comes to the effectiveness of a therapeutic intervention. Features that influence compliance are demographic characteristics, side effects of the therapy, how simple the intake of the medication is, costs of the medication, and the number of pills to be taken $[19,20]$. The importance of the latter has been underlined by the results of the present study. Approximately 
half of the patients stated that they were concerned about accidentally forgetting pills, or taking the wrong pills or the wrong dose of their pills. This concern increased with increasing pill burden and increasing age. If patients take the wrong pills, the wrong dose of pills, or too many pills, this could result in safety issues, especially in light of advanced age and comorbidities. Especially when multiple generic versions of a drug are available, patients may be exposed to a frequent change in the appearance of their drugs. Potential pharmacy dispensing errors may then not be apparent for the patients anymore and patients themselves may mistake one drug for another. Also, forgetting pills could reduce the effects of their treatment as the medication is not administered in the optimal dose range.

Generally, polypharmacy, defined as the use of five or more medications, is a problem in patients as it increases the possibility of experiencing adverse effects from multiple treatments [21-26]. Thus, several approaches to reduce polypharmacy have been explored. Interventions, such as computerized decision support or complex, multifaceted pharmaceutical care, showed reductions in the summated Medication Appropriateness Index and in the number of Beers drugs per patient, and a significant reduction in the number of adverse drug events [26]. However, it was unclear if the intervention also resulted in a clinically significant improvement [26]. Another approach, Good Palliative-Geriatric Practice algorithm for drug discontinuation, was developed by Garfinkel et al. in a prospective interventional study [27]. Successful discontinuation of drugs was achieved in $81 \%$ of patients. Of the discontinued drug therapies, $2 \%$ were restarted because of recurrence of the original indication. A total of $88 \%$ of patients reported global improvement in health. However, this tool still needs to be tested in randomized controlled trials. Some researchers conclude that - despite all the criteria and algorithms available - reducing polypharmacy and avoiding inappropriate medications is a highly individualized process, which is different for each patient, and clinicians will have to use extensive clinical judgment [28]. Thus, taken together, adequate therapeutic intervention in patients with hypertension will need to be effective and safe while not adding to the pill burden that already seems to be high in this patient population, which often also suffers from additional comorbidities.

Among the potential weaknesses of the present study is the fact that the questionnaire used was not a validated questionnaire and, thus, cannot be used to compare with results from other studies e.g., in other countries. Another issue to keep in mind when interpreting the study data is the fact that the patients filled in the questionnaires at the first visit of an observational study that specifically included patients whom their physician had decided to treat with the triple therapy $\mathrm{A}+\mathrm{V}+\mathrm{H}$. This could lead to a selection bias, with the treating physician mainly including the more "severe" cases because they are more likely to need a triple combination. The questionnaires were applied at the start of the study; therefore, it simply evaluates the situation of the individual at the beginning of the study, and it is not possible to assess if and how treatment with $\mathrm{A}+\mathrm{V}+\mathrm{H}$ would have impacted the responses.

A considerable strength of the results presented is the large number of patients and physicians included. The setting of the study allowed the authors to collect data in a reallife situation, which provides information on typical patient characteristics and current treatment approaches [29-31]. It also provided a sufficiently large sample size to allow for analysis of differences between the subgroups, e.g., by 
number of total pills daily or by age group. The number of patients was similar to the number that was used in the retrospective study on predictors of adherence with antihypertensive (and lipid-lowering) treatment in the US [12].

\section{CONCLUSION}

In conclusion, a high number of pills is considered a burden by patients. This burden increases with the number of pills taken per day and needs to be actively addressed, especially in elderly patients and those with comorbidities. Further research is necessary to evaluate which approaches may be most promising.

\section{ACKNOWLEDGMENTS}

The authors acknowledge the cooperation of the patients, investigators, and staff at all participating sites of this study. This study and the article publication charges were funded by Novartis Pharma GmbH. Financial support for medical editorial assistance was provided by Novartis Pharma GmbH. The authors thank Franziska Pirkl, PhD, for her medical editorial assistance with this manuscript on behalf of Kantar Health GmbH. Dr. Klebs is the guarantor for this article, and takes responsibility for the integrity of the work.

Conflicts of interest. Andreas Hagendorff has received research funding from GE Healthcare and Novartis, and lecture fees from GE Healthcare, Philips, Siemens, Toshiba, Servier, and Novartis. Siegfried Freytag is employed by Kantar Health GmbH, which conducted the studies and the analysis on behalf of Novartis Pharma GmbH. Alfons Müller is an employee of Novartis Pharma $\mathrm{GmbH}$. Sven Klebs is an employee of Novartis Pharma GmbH. The study has been registered according to local regulations in a German register (www.vfa.de/de/arzneimittel-forschung/ datenbanken-zu-arzneimitteln/nisdb/

nis-details/_382).

Compliance with Ethics Guidelines. The study was notified in accordance with $\S 67$ (6) German Drugs Law (AMG) and conducted according to the applicable regulatory requirements and recommendations. All procedures followed were in accordance with the ethical standards of the responsible committee on human experimentation (institutional and national) and with the Helsinki Declaration of 1975 , as revised in 2000 , and as far as applicable for observational, noninterventional studies. Informed consent was obtained from all patients for being included in the study.

Open Access. This article is distributed under the terms of the Creative Commons Attribution Noncommercial License which permits any noncommercial use, distribution, and reproduction in any medium, provided the original author(s) and source are credited.

\section{REFERENCES}

1. Kones R. Primary prevention of coronary heart disease: integration of new data, evolving views, revised goals, and role of rosuvastatin in management. A comprehensive survey. Drug Des Devel Ther. 2011;5:325-80.

2. Kearney P, Whelton M, Reynolds K, Muntner P, Whelton P, He J. Global burden of hypertension: Analysis of worldwide data. Lancet. 2005;365:217-23.

3. Wolf-Maier K, Cooper RS, Kramer $\mathrm{H}$, et al. Hypertension treatment and control in five European countries, Canada, and the United States. Hypertension. 2004;43:10-7.

4. Law MR, Morris JK, Wald NJ. Use of blood pressure lowering drugs in the prevention of cardiovascular disease: meta-analysis of 147 randomised trials in the context of expectations from prospective epidemiological studies. BMJ. 2009;338:b1665.

5. Pepine CJ, Handberg EM, Cooper-DeHoff RM, et al; INVEST Investigators. A calcium antagonist vs 
a non-calcium antagonist hypertension treatment strategy for patients with coronary artery disease. The International Verapamil-Trandolapril Study (INVEST): a randomized controlled trial. JAMA. 2003;290:2805-16.

6. Bakris GL. The importance of blood pressure control in the patient with diabetes. Am J Med. 2004;116(Suppl. 5A):30S-8S.

7. Dahlöf B, Sever PS, Poulter NR, et al; ASCOT Investigators. Prevention of cardiovascular events with an antihypertensive regimen of amlodipine adding perindopril as required versus atenolol adding bendroflumethiazide as required, in the Anglo-Scandinavian Cardiac Outcomes TrialBlood Pressure Lowering Arm (ASCOT-BPLA): a multicentre randomised controlled trial. Lancet 2005;366:895-906.

8. Jamerson K, Bakris GL, Dahlöf $\mathrm{B}$, et al; ACCOMPLISH Investigators. Exceptional early blood pressure control rates: the ACCOMPLISH trial. Blood Press. 2007;16:80-6.

9. Jamerson K, Weber MA, Bakris GL, et al; ACCOMPLISH Investigators. Benazepril plus amlodipine or hydrochlorothiazide for hypertension in high-risk patients. N Engl J Med. 2008;359:2417-28.

10. DiMatteo MR, Giordani PJ, Lepper HS, Croghan TW. Patient adherence and medical treatment outcomes: a meta-analysis. Med Care. 2002;40:794-811.

11. Ho PM, Magid DJ, Shetterly SM, et al. Medication nonadherence is associated with a broad range of adverse outcomes in patients with coronary artery disease. Am Heart J. 2008;155:772-9.

12. Chapman RH, Benner JS, Petrilla AA, et al. Predictors of adherence with antihypertensive and lipid-lowering therapy. Arch Intern Med. 2005;165:1147-52.

13. Rottlaender D, Scherner $M$, Schneider $T$, Erdmann E. [Multimedikation, compliance und zusatzmedikation bei patienten mit kardiovaskulären erkrankungen]. Dtsch Med Wochenschr. 2007;132:139-44. In German.

14. Mancia G, De BG, Dominiczak A, et al; the Task Force for the Management of Arterial Hypertension of the European Society of Hypertension; the Task Force for the Management of Arterial Hypertension of the European Society of Cardiology. Guidelines for the Management of Arterial Hypertension: The Task Force for the Management of Arterial Hypertension of the European Society of
Hypertension (ESH) and of the European Society of Cardiology (ESC). Eur Heart J. 2007;28:1462-536.

15. Volpe M, Chin D, Paneni F. The challenge of polypharmacy in cardiovascular medicine. Fundam Clin Pharmacol. 2010;24:9-17.

16. Theobald K, Capan M, Herbold M, Schinzel S, Hundt F. Quality assurance in non-interventional studies. GMS Ger Med Sci. 2009; 7:Doc 29.

17. Lüders S, Schrader J, Schmieder RE, Smolka W, Wegscheider K, Bestehorn K. Improvement of hypertension management by structured physician education and feedback system: cluster randomized trial. Eur J Cardiovasc Prev Rehabil. 2010;17:271-9.

18. Qureshi NN, Hatcher J, Chaturvedi N, Jafar TH. Effect of general practitioner education on adherence to antihypertensive drugs: cluster randomized controlled trial. BMJ. 2007;335:1030.

19. Adherence to long-term therapies. Evidence for action. 2003. World Health Organization website. Available at: http://whqlibdoc.who.int/ publications/2003/9241545992.pdf. Accessed Mar 122013.

20. Neutel JM, Smith DHG. Improving patient compliance: a major goal in the management of hypertension. J Clin Hypertens. 2003;5:127-32.

21. Cadieux RJ. Drug interactions in the elderly. How multiple drug use increases risk exponentially. Postgrad Med. 1989;86:179-86.

22. Fux R, Greiner D, Geldmacher M, Mörike K, Gleiter $\mathrm{CH}$. Multiple drug prescribing by general practitioners in a German region: Implications for drug interactions and patient safety. Int J Clin Pharmacol Ther. 2006;44:539-47.

23. Nguyen JK, Fouts MM, Kotabe SE, Lo E. Polypharmacy as a risk factor for adverse drug reactions in geriatric nursing home residents. Am J Geriatr Pharmacother. 2006;4:36-41.

24. Jesson B. Minimising the risk of polypharmacy. Nurs Older People. 2011;23:14-20.

25. Wehling M. Guideline-driven polypharmacy in elderly, multimorbid patients is basically flawed: there are almost no guidelines for these patients. J Am Geriatr Soc. 2011;59:376-7.

26. Patterson SM, Hughes C, Kerse N, Cardwell CR, Bradley MC. Interventions to improve the appropriate use of polypharmacy for older people. Cochrane Database Syst Rev. 2012;5:CD008165. 
27. Garfinkel D, Mangin D. Feasibility study of a systematic approach for discontinuation of multiple medications in older adults: addressing polypharmacy. Arch Intern Med. 2010;170:1648-54.

28. Gokula M, Holmes HM. Tools to reduce polypharmacy. Clin Geriatr Med. 2012;28:323-41.

29. Black N. Why we need observational studies to evaluate the effectiveness of health care. BMJ. 1996;312:1215-8.
30. von Elm E, Altman DG, Egger M, Pocock SJ, Gøtzsche PC, Vandenbroucke JP; STROBE Initiative. The Strengthening the Reporting of Observational Studies in Epidemiology (STROBE) statement: guidelines for reporting observational studies. J Clin Epidemiol. 2008;61:344-9.

31. Silverman SL. From randomized controlled trials to observational studies. Am J Med. 2009;122:114-20. 